\section{Revista Brasileira de Literatura Comparada abralic}

ISSN 0103-6963

e-ISSN 2596-304X

EDITOR-CHEFE:

Rachel Esteves Lima

EDITOR EXECUTIVO:

Regina Zilberman

SUBMETIDO: 08.10 .2021

ACEITO: 05.11.2021

\section{COMO CITAR:}

LEAL, Marcelle Ferreira.

Deslocamentes: Carolina

Maria de Jesus em viagem

pela América Latina.

Revista Brasileira de

Literatura Comparada, v. 24 , n. 45 , p. 17-30, jan./ abr., 2022. doi: https:// doi.org/10.1590/2596$304 \times 20222445 \mathrm{mfl}$

http:// www.scielo.br/rblc https://revista.abralic.org.br

\title{
Deslocamentes: Carolina Maria de JESUS EM VIAgEM PELA AMÉRICA LATINA
}

\author{
Displaceminds: Carolina Maria de Jesus on a Trip Through Latin America \\ Desplazamentes: Carolina Maria de Jesus en Viaje por Latinoamérica
}

\author{
MARCelle Ferreira Leal ${ }^{1}$ \\ ${ }^{1}$ Universidade Federal do Rio de Janeiro. Rio de Janeiro, RJ, Brasil. \\ E-mail:marcellefleal@gmail.com
}

\section{RESUMO}

Carolina Maria de Jesus viaja pela América Latina para a divulgação do livro Quarto de despejo nos anos 1960. Os registros da trajetória por Argentina, Uruguai e Chile constam em Diario de viaje, apêndice presente em uma das traduções de Casa de Alvenaria para o espanhol. No percurso, a escritora brasileira tece uma série de análises sobre suas impressões a respeito de cada local e propicia a contemplação dos países a partir do ponto de vista de uma intelectual preta, periférica e oriunda do Sul global. Através da inscrição dos movimentos diversos que realiza, permite um cotejo comparativo das formas pelas quais afeta e é afetada em cada território por onde transita e efetua o que designamos deslocamentes. Acredita-se que, ao promover um diálogo entre suas vivências no exterior, contribuímos não só para o enriquecimento da fortuna crítica do percurso internacional da autora, mas também discutimos a relevância dos deslocamentos de intelectuais negras e negros latino-americanas (os) pela região com o fim de debatê-la internamente e desvelá-la em seus temas e problemas mais intrínsecos.

PALAVRAS-CHAVE: Literatura Latino-americana; Literatura Brasileira; Carolina Maria de Jesus; relato de viagem; deslocamentos.

\section{ABSTRACT}

Carolina Maria de Jesus travels throughout Latin America to promote the book Quarto de Despejo in the 1960s. The records of her trip to Argentina, Uruguay and Chile are in Diario de viaje, an appendix included in one of the translations of Casa de Alvenaria into Spanish. On the way, the Brazilian writer produces a series of analyses concerning her impressions about each place and provides a perspective of the countries from the point of view of a black intellectual and peripheral woman from the global South. Considering the movements that Carolina makes, it is possible to compare the ways through which she affects each place where she goes and how she is affected by them, producing what we call displaceminds. It is believed that, promoting a dialogue between her experiences abroad, we not only contribute to the enrichment of the critical fortune of the author's international career, but we also discuss the relevance of the displacement of Black Latin American intellectuals through the region in order to debate it internally and unveil it in its most intrinsic themes and problems.

KEYWORDS: Latin American literature, Brazilian literature, Carolina Maria de Jesus, travel narratives, displacement.

\section{RESUMEN}

Carolina Maria de Jesus viaja por Latinoamérica para la divulgación del libro Quarto de despejo en los años 1960. Los registros de su trayectoria por Argentina, Uruguay y Chile están en el Diario de viaje, apéndice presente en una de las traducciones de Casa de Alvenaria para el español. En la ruta, la escritora brasileña elabora una serie de análisis sobre la realidad que encuentra en cada país y nos posibilita contemplarlos a partir de la perspectiva de una intelectual negra, periférica y originaria del sur global. A través de la inscripción de los movimientos diversos que realiza, nos permite un cotejo comparativo de los medios por las cuales ella afecta y se afecta en cada 
territorio que recorre y efectúa lo que nombramos desplazamentes. Se cree que, al promover el diálogo entre sus vivencias en el exterior, contribuimos no solo para aportar informaciones a la fortuna crítica sobre la trayectoria internacional de la autora, sino también para discutir la relevancia de los desplazamientos de intelectuales negras y negros latinoamericanas(os) por la región con el fin de discutirla desde adentro y desvelarla en sus temas y problemas más intrínsecos.

PALABRAS CLAVE: Literatura Latinoamericana; Literatura Brasileña; Carolina Maria de Jesus; relato de viaje; desplazamientos.

\author{
Eu sou um monte de \\ constelações \\ brilhando e ardendo \\ mas nem todo mundo \\ sabe ver \\ ou só vê a parte que arde \\ ou só vê a parte que brilha \\ (Ryane Leão) ${ }^{1}$
}

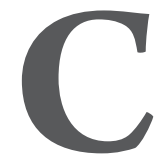

arolina Maria de Jesus é uma escritora brasileira conhecida nacional e internacionalmente pela originalidade de sua obra. A produção da autora é ampla e abarca gêneros diversos, mas o fio da escrevivência ${ }^{2}$ atravessa cada escrito e confere coerência ao todo. O uso da palavra coerência, não unicidade, justifica-se porque, diferente das obras de arte cuja forma se apresenta em singularidade, a criação de Carolina de Jesus se desenvolve em pluralidades. Digo, os textos estão em muitos papéis, cadernos e gravações; dispersos em diversos locais, exigem empenho de editores e pesquisadores na tarefa de ordená-los. Ademais, os materiais demandam dos leitores uma atividade atenta capaz de encontrar as linhas que atam seus fragmentos. Esta rede se combina em inúmeras possibilidades e a escritora de Sacramento demonstra, ainda hoje, a capacidade de seguir criando multiversos e de se manter insubmissa aos sistemas ordenados.

Contudo, é imprescindível não romantizar a descentralização dos originais. O resgate da reconstituição política e socioeconômica do Brasil após a invasão europeia demonstra que o racismo é estrutural e estruturante na formação da ordem implementada. Segundo Silvio Almeida, "como processo histórico e político, [o racismo] cria as condições sociais para que, direta ou indiretamente, grupos racialmente identificados sejam discriminados de forma sistemática” (ALMEIDA, 2019, p. 51). Quando se trata da população negra, o apartar se desenvolve de forma que os sujeitos de pele preta são excluídos, apagados, violentados ou reduzidos a estereótipos que os subjugam. Logo, entende-se que a negligência da preservação e organização do legado Carolina Maria de Jesus, constantemente denunciada por pesquisadores, relaciona-se às identidades que a atravessam de mulher negra, moradora

1 LEÃO, 2017, n.p.

2 Termo cunhado pela escritora Conceição Evaristo para designar a escrita que nasce da experiência. 
da favela em parte de sua existência e oriunda das classes populares. Digo, o racismo, o classismo e o machismo são as principais causas do descaso público com a conservação de sua memória.

O diário de viagem produzido pela autora com a finalidade de registrar a trajetória por Argentina, Uruguai e Chile entre os anos 1961 e 1962 ilustra o debate anterior. O texto figura como um apêndice de Casa de Ladrillos, tradução para o espanhol do livro Casa de Alvenaria, publicado em Buenos Aires, pela editora Abraxas, em 1963. Até o momento de redação do artigo, o destino atual dos originais é desconhecido, o acesso ao conteúdo se restringe à versão em língua espanhola e ainda não há uma edição em português dos escritos disponível no mercado editorial. Estes fatores contribuem para a escassez crítica sobre um evento relevante tanto para a biografia carolineana quanto para os domínios dos movimentos feministas negros e da historiografia e teoria literárias latinoamericanas: a viagem de uma mulher preta de origem popular para a divulgação da Literatura Brasileira no exterior.

Acredita-se que o debate sobre o trânsito internacional da escritora pelo Cone Sul preenche uma lacuna existente nas pesquisas sobre sua obra. Propõe-se, visando ao objetivo descrito, a elaboração de uma análise comparativa da passagem de Carolina Maria de Jesus pelos três países a partir dos seguintes aspectos: a viajante e a intelectual. Posteriormente, almeja-se apresentar o conceito deslocamentes que nos remete à reconfiguração da ordem em vigor a partir do movimento físico e reflexivo de pensadores periféricos por espaços tradicionalmente interditados, direta ou indiretamente, aos seus corpos e ideias. Entende-se que a passagem pelos territórios vizinhos dá visibilidade às necessidades daqueles que estão restritos aos quartos de despejo dos grandes centros e às potências criativo-epistemológicas de quem se cria em espaços marginalizados. Além disso, derruba o monumento da estereotipia que insiste em simular perfis distorcidos dos povos austrais.

\title{
A BORDO: A TURISTA CAROLINA MARIA DE JESUS
}

\author{
Después que \\ publiqué mi libro \\ "Quarto de despejo" \\ me convertí en \\ gitana. Estoy siempre \\ viajando. \\ (Carolina Maria de Jesus)
}

Carolina Maria de Jesus é uma viajante interessada em descobrir as particularidades dos lugares que visita. $\mathrm{O}$ diário de viagem comprova a afirmação, pois expressa as vivências de uma turista que se empenha em desvendar o espaço, a população e a cultura de onde frequenta. Através de uma escrita poética e crítica, característica de sua obra, desvela as experiências nos âmbitos aparentes e subjetivos, e permite ao leitor não só a elucidação dos eventos ocorridos na trajetória internacional, mas também a compreensão da autora sobre os fatos. É um material através do qual se verifica a união da inquietação intelectual e a curiosidade de perscrutar sociedades distintas. Assim, possibilita um conhecimento mais amplo sobre a escritora e os locais, uma vez que ambos se afetam a partir do contato estabelecido. 
Os escritos elaborados durante o percurso no exterior contêm informações que propiciam reelaborar sua rota a partir de perspectivas diversas. No presente tópico, a análise se concentra no âmbito de Carolina Maria de Jesus como uma turista que explora o entorno e descreve os atrativos das cidades por onde passa. Acredita-se que, ao abordá-la enquanto viajante, contribui-se para o fortalecimento da legitimidade do corpo preto e periférico como sujeito em deslocamento internacional e a ressignificação da presença da mulher negra no exterior. Embora o trânsito se realize com o fim de divulgar o livro Quarto de Despejo em alguns países do Cone Sul, há espaços na agenda para conhecer lugares, provar comidas e interagir com a população. A apresentação dos tópicos se realizará na ordem cronológica da viagem: Argentina, Uruguai e Chile.

A respeito da observação dos espaços, destaca-se o contato inicial da autora com os respectivos países, isto é, a chegada no aeroporto, quando pisa pela primeira vez nos territórios vizinhos. Em Buenos Aires, menciona a presença da tradutora do livro, de jornalistas e fotógrafos. No desembarque, concede as primeiras entrevistas e ressalta a amabilidade e a integridade dos funcionários. Além disso, nota que a área está debaixo de uma ponte, sente-se confusa pela percepção de dois idiomas simultaneamente, o português e o espanhol, e assinala a ausência de negros, tema que se repetirá em outros trechos do diário. A descrição da chegada em Montevidéu é mais breve. Na capital uruguaia, restringe-se em assinalar a recepção da responsável pela transposição do livro ao idioma estrangeiro e cita o Sr. Medina, dono da editora homônima, como o anfitrião da visita. Em Santiago, desembarca em Los Cerrillos e diz que o entorno lhe parece uma planície natural. No entanto, a acolhida é desagradável, posto que o senhor que a recepciona, cujo nome não é mencionado, diz para um colega "Olha que coisa linda! ...Solteira e com três filhos." (JESUS, 1963, p. 168) ${ }^{3}$. Ela entende a frase e demonstra decepção, pois a expectativa do trajeto é atravessada pelo machismo.

Segundo o ditado popular, a primeira impressão é a que fica. Então, se seguimos a sabedoria do povo, cada recepção se configura como um resumo da estadia posterior. Na Argentina, Carolina Maria de Jesus interage com diversas mídias, estabelece pontes com a realidade brasileira, está atenta à aparente ausência de negras e negros no país, indica constantemente o tratamento gentil recebido e se reconhece como uma escritora de prestígio. No que concerne ao Uruguai, em comparação aos vizinhos, a passagem é bem mais breve, tendo em vista que, de acordo com o diário em análise, a autora não retorna ao país, diferente dos demais. Nota-se que há um tom mais oficial e se estabelece uma relação mais próxima com o presidente da época, Victor Haedo, e com os funcionários consulares. No Chile, a natureza é enfatizada e, na primeira ida à Santiago, os episódios machistas, classistas e racistas são recorrentes no relato. É fundamental assinalar que os eventos narrados não se restringem aos mencionados, mas trazem alguns indícios do que se encontrará no percurso.

Enquanto turista, ela contempla os aspectos naturais que constituem os espaços que atravessa, como a beleza do rio da Prata, das águas termais uruguaias e da Cordilheira dos Andes. Também demonstra encantamento por elementos frequentemente mencionados em seu trabalho, como a figura dos pássaros e das flores. Vale lembrar que a poética carolineana é marcada pela relação estética com o meio em que está. Logo, a inscrição dos dias no exterior é elaborada com a mesma lírica presente em outras produções e muitas vezes entrelaçada a uma voz crítica. Apresento alguns exemplos: "Acordei

3 ¡Linda cosa!... ¡Soltera y con tres hijos!... (Tradução nossa). 
com a sinfonia dos pássaros”, diz em Mendoza (JESUS, 1963, p. 165); em Salto, reflete: "Eu estava admirada vendo o brotar da água quente do solo. Pensei que o homem é mau, mas que a natureza o ama. A terra dá pro homem tudo o que pode" (JESUS, 1963, p. 158) ; "Que cidade bonita é Concepción! As serras são verdes e tem muitas flores” (JESUS, 1963, p. 178) ${ }^{6}$; "Estava com muito frio. Tinha a impressão de estar no Polo Norte, em um iceberg” (JESUS, 1963, p. 176) ${ }^{7}$, em que descreve não só o clima de Santiago, mas o momento no qual sofre um episódio claro de racismo, que será apresentado no próximo tópico. Frequentemente, a reverência idílica ao belo é atravessada pela consciência áspera de uma realidade que não lhe permite escapar de suas esferas.

A gastronomia é outro âmbito de realce nos registros. Ela fica impressionada com o paladar dos alimentos de cada país e, geralmente, atribui adjetivos para qualificá-los ou expressa a sensação provocada pela degustação. Demonstra fascínio pelo sabor da vianda argentina - "fiquei admirada com o sabor da carne" (JESUS, 1963, p. 132) ${ }^{8}$ - e caracteriza, diversas vezes, a comida do país como reconfortante. $\mathrm{O}$ apreço pela culinária rio-platense torna-se explícito quando, no dia 17 de novembro, menciona que está engordando. No Uruguai, há tanto indicações genéricas de coisas que provou - guloseimas, doces, licores - quanto específicas, como o churrasco e a feijoada. Porém, o sorvete ganha destaque: "Que sorvete gostoso! Era feito com leite puro." (JESUS, 1963, p. 155) ${ }^{9}$. No Chile, relata um evento no qual narra o assombro das pessoas quando come abacate com limão e açúcar. Após expor os comentários dos que estavam presentes sobre ser estrangeira, indica para o leitor: "É que aqui no Chile comem abacate com sal” (JESUS, 1963, p. 174). Ademais, come sopa, pão, salada e pratos típicos chilenos, os últimos consumidos em um restaurante onde Pablo Neruda estava presente com a esposa. Embora tenha sido convidada para se unir à mesa do poeta, nega a gentileza, posto que a intelectual brasileira estava acompanhada do professor Mendoza.

Nota-se a preocupação de Carolina Maria de Jesus em representar as percepções visuais e gustativas experimentadas. Desta maneira, cria memórias afetivas a partir do que descobre por meio da visualização e alimentação. Enquanto turista, explora os cenários em todas as possibilidades e demonstra sensibilidade para representá-los. Seja através do que observa ou do que ingere, registra cada captação pelos sentidos como um meio de criar lembranças para si e de permitir ao leitor - indiferente de onde esteja - ser um companheiro de viagem que vai desbravar a rota através do que a artista traduz. À luz de Grada Kilomba, compreende-se que o ato de escrever ao longo da viagem afirma sua posição de sujeito e confronta o sistema colonial, uma vez que ela se coloca como um corpo preto periférico e pertencente a qualquer meio onde deseje estar. Cito a teórica portuguesa: “[... enquanto escrevo, eu me torno a narradora e a escritora da minha própria realidade, a autora e a autoridade na minha própria história. Nesse sentido, eu me torno a oposição do que o projeto colonial predeterminou" (KILOMBA, 2019, p. 28). Portanto, no rastro deste pensamento, constata-se que esta mulher negra assume a representação de si e de suas impressões como viajante.

\footnotetext{
4 Me desperté con la sinfonía de los pájaros. (Tradução nossa).

5 Yo estaba admirada viendo manar el agua caliente del suelo. Pensé que el hombre es malo, pero que la naturaleza lo ama. La tierra le da al hombre todo lo que puede. (Tradução nossa).

6 ¡Qué ciudad bonita es Concepción! Las sierras son verdes y hay muchas flores. (Tradução nossa).

7 Sentía mucho frío. Tenía la impresión de estar en el Polo Norte, en un iceberg. (Tradução nossa).

8 [...] quedé admirada con el sabor de la carne (Tradução nossa).

9 ¡Qué helado tan rico! Estaba hecho con leche pura. (Tradução nossa).
} 
Retomando os tópicos do diário, no que concerne aos encontros, a viagem propicia contatos diversos. Seja em festas, entrevistas ou visitas pessoais, personalidades e pessoas comuns tem acesso à escritora de Sacramento. De uma maneira mais abrangente, utiliza adjetivos como "amável”, "elegante" e "inteligentíssimo" para descrever os argentinos, além de exaltar o gosto que eles tem pela cultura. Repete o termo "elegante" para apresentar os uruguaios e os caracteriza como um povo "calmo e tranquilo", ademais de registrar sua humanidade, posto que observa uma maior assistência aos moradores de áreas mais pobres do que em outros lugares. A relação com os chilenos é narrada com mais dor. No dia 25 de dezembro, escreve: "Alguns rostos eram tristes, outros alegres. O meu era um dos tristes (JESUS, 1963, p. 173) ${ }^{10}$.

Consoante ao dito anteriormente, o motivo principal do deslocamento é a promoção de Quarto de despejo. Portanto, a maior parte da agenda escritora consiste em sessões de autógrafos, participações midiáticas e presença em eventos oficiais. Os encontros possibilitam trocas não só intelectuais e existenciais, mas de presentes também. A autora recebe visitas do pintor Viscardo de Sardi, que lhe dá um quadro intitulado Misericordia, do escritor Bernardo Verbitsky e dá um passeio com o poeta Gustavo Soler. Relata que recebe muitos livros em terras uruguaias e ganha um poema de Pablo Neruda no Chile. No entanto, em alguns momentos, a agitação social não impede que ela tenha momentos reflexivos, nos quais expressa os sentimentos em relação ao que vive. Ressalto três trechos apresentados em cada um dos países: "A tarde de autógrafos foi muito movimentada. Eu parava de escrever e olhava essas pessoas fortes que me olhavam e me admiravam. Todos sorriam". (JESUS, 1963, p. 147)"11; Vários negros foram comprar meu livro. Me olhavam e sorriam. Eu tinha a impressão de estar sonhando. (JESUS, 1963, p. 155)"12; Eu não achei que a vida de um escritor fosse tão confusa. Esse é meu primeiro ano de vida literária. Estou debutando. Observando, olhando, analisando (JESUS, 1963, p. 173 $)^{13}$. Constantemente, o burburinho externo é substituído pela voz interna de uma mulher cuja vida é atravessada por mudanças profundas.

Conforme se observa, a interação com o espaço, a cultura e as pessoas é apresentada com contentamento. Carolina Maria de Jesus é uma viajante interessada em desbravar o novo e se entrega à visita. $\mathrm{O}$ intercâmbio está presente em sua trajetória, pois vivencia o local e oferece um pouco do Brasil para o exterior. Em uma favela da Argentina, por exemplo, leva café para os moradores. Na turnê promocional, também divulga seus textos, poemas e músicas por onde passa. Além disso, dá inúmeras entrevistas e é presenteada com obras de arte por artistas estrangeiros. Há uma troca intensa provocada pelo deslocamento desta intelectual negra. Assim, entende-se que ela representa não só a cultura, mas também a sociedade brasileira no âmbito internacional. A escritora configura o corpo da base populacional que constitui o país, ocupa o lugar de fala que leva para o mundo a realidade que vivemos e anuncia a possibilidade de reconstrução da América Latina a partir de sua pluralidade em relações colaborativas dos indivíduos entre si e em relação com a natureza.

10 Algunas caras eran tristes, otras alegres. La mía era una de las tristes. (Tradução nossa).

11 La tarde de autógrafos fue muy concurrida. Yo paraba de escribir y miraba a ese pueblo fuerte que me miraba y me admiraba. Todos sonreían. (Tradução nossa).

12 Varios negros fueron a comprar mi libro. Me miraban y sonreían. Yo tenía la impresión de estar soñando. (Tradução nossa).

13 Yo no pensé que la vida de un escritor fuese tan confusa. Este es mi primer año de vida literaria. Estoy en el noviciado. Observando, mirando, analizando.(Tradução nossa). 


\title{
DESLOCAMENTES DE UMA INTELECTUAL PELA AMÉRICA LATINA
}

\author{
Cuando mi libro "Quarto de despejo" aparece en algún \\ lugar, agita el problema social local porque es el \\ estandarte de los pobres. \\ (Carolina Maria de Jesus)
}

O tópico anterior dedica-se à exposição da presença de Carolina Maria de Jesus como viajante na qual se privilegiam as interações da autora em contexto internacional. Contudo, é imprescindível assinalar que os registros não expressam uma experiência exclusivamente idílica. É importante lembrar que Carolina Maria de Jesus é uma mulher cuja constituição existencial elabora-se onde ela designa como quarto de despejo da cidade. Devido ao espaço que ocupa em grande parte da vida, configura-se como uma outsider within, conceito de Patricia Hill Collins (2016), que corresponde àquela que não faz parte do meio, mas o frequenta com uma visão externa, e por isso o decodifica com mais facilidade. Atenta à importância das margens para compreender o centro, a escritora se interessa em ter contato com o que está para além do que é visível para um turista e tem consciência do valor do seu olhar sobre os ambientes, uma vez que ocupa uma perspectiva distinta.

Enquanto intelectual, perscruta com curiosidade os territórios vizinhos e elabora reflexões sobre a realidade e potencialidade de cada um em cotejo com os aspectos do próprio país. Assim como as demais obras carolineanas, o Diario de viaje exibe uma escrita comprometida com a exposição de denúncias sobre as desigualdades sociais que testemunha e de propostas para solucioná-las. Digo, há uma postura ativa na qual assume a responsabilidade de anunciar saídas para os problemas que identifica. O material a respeito da sua trajetória internacional estabelece uma interconexão regional do que observa. Percorrer os países consecutivamente propicia o desenvolvimento de análises comparativas que contribuem para o debate sobre questões que concernem às sociedades latino-americanas.

Verifica-se, já no itinerário, um dado relevante, a visita não se restringe às capitais: Buenos Aires, Montevidéu e Santiago. Na Argentina, vai à Rosário, Córdoba e Mendoza; no Uruguai, visita Salto; no Chile, conhece Concepción. O trânsito tampouco se limita às áreas turísticas. Ela se desloca para conhecer villas, cantegriles, callampas, ou seja, tem contato com as favelas de cada um destes países. Este movimento é fundamental para uma análise local mais ampla, visto que ela transita do centro em direção às periferias. No dia 17 de dezembro de 1961, quando sai de aeronave da Argentina, declara: "Quando o avião decolou eu ia olhando as cidades com suas matas e seus edifícios tão altos e tão modernos. Acho que se Adão voltasse ao mundo, ficaria louco com estas confusões que os homens atuais dizem que é progresso" (JESUS, 1963, p. 162 ${ }^{14}$. Ela está consciente de que os núcleos metropolitanos concentram as incongruências do desenvolvimento. Logo, a possibilidade de abarcar o que transborda das capitais oferece uma visão mais completa do que está à luz e à sombra de sua constituição.

Na trajetória, não só a beleza é assinalada, mas também a existência de terras ociosas. Observado pelo olhar de quem viveu em condições precárias e passou fome, o espaço é contemplado pela perspectiva da construção de casas populares e do cultivo do solo. Na Argentina, o problema da moradia é

14 Cuando el avión partió yo iba mirando las ciudades con sus arboledas y sus edificios tan altos y tan modernos. Creo que si Adán volviese al mundo se pondría loco con estas confusiones que los hombres actuales dicen que es progreso. (Tradução nossa). 
constantemente reiterado. De acordo com o que observa e dialoga com os locais, "a construção é caríssima e os aluguéis muito elevados" (JESUS, 1963, p. 140) ${ }^{15}$. Ela estabelece uma relação comparativa do território vizinho com o Brasil onde tanto as favelas quanto a dificuldade de acesso às habitações se assemelham. Porém, no que tange à alimentação, entende que há uma diferença, já que, enquanto vê abundância de trigo e gado em solo argentino, indica que no território brasileiro: "A moradia é o juiz, e a fome o réu" (JESUS, 1963, p. 140) ${ }^{16}$. Embora tenha sua tese refutada em Rosário, quando um grupo de jornalistas diverge sobre a existência de fome, exemplificando com a situação do norte do país, reitera que é uma incongruência devido à abundância alimentícia presente. Na favela uruguaia, detecta parte do solo inutilizado e identifica terras férteis abandonadas. Ela assinala o gosto do homem atual pelas cidades e fala para os mais pobres sobre a necessidade de plantar feijões, verduras e criar galinhas. No Chile, o custo alto também é identificado como uma das causas da precarização da vida. Conforme dito, a detecção do problema é sucedida por uma solução, o que torna a leitura elucidativa e propositiva.

Ainda em referência às reflexões mencionadas, vale reiterar uma conversa em seu hotel, no dia 24 de novembro de 1961, sobre ambos os temas. Inicialmente, escreve no diário: "Quando voltei ao hotel, encontrei uma senhora que veio me cumprimentar. Me disse que o problema em Buenos Aires é a falta de moradias. Que os aluguéis são muito caros” (JESUS, 1963, p. 150) ${ }^{17}$. Entende-se que havia uma única pessoa, porém no momento da despedida, registra: "Me despedi das mulheres que tinham vindo e uma me beijou" (JESUS, 1963, p. 151) ${ }^{18}$. No entanto, o trecho revela mais do que uma imprecisão na quantidade de pessoas, pois, em seguida, há uma explanação breve sobre as condições sociais presentes, mas apresentada em discurso indireto. Portanto, cria-se uma ambiguidade, ou melhor, um amalgamar das falas da autora com a(s) interlocutora(s) quando expressa:

O salário não dá para pagar uma habitação decente. Se se paga o aluguel, não se pode comprar comida. A quem podem recorrer os jovens para que lhe deem comida? Depois de um tempo, não tem dinheiro, não tem saúde, não tem moral. Os jovens não podem realizar seus sonhos, não podem se casar nem ter um lar porque o salário não dá. A vida vai entristecendo eles. E se transformam em farrapos humanos. Os governos constroem casas pré-fabricadas. Mas esta não é a solução. Os ricos enviam suas contribuições aos pobres. Mas é preciso que haja uma reorganização. Precisamos de um mundo que tenha menos sofrimento e mais fraternidade. Aqui na Argentina o frio é muito forte e tem homens e mulheres que dormem embaixo das árvores. Dizem que o povo da atualidade é civilizado. Só que um homem civilizado não pode permitir que outro homem durma embaixo de uma árvore. (JESUS, 1963, p. 151) ${ }^{19}$

\footnotetext{
15 “[...] la construcción es carísima y los alquileres muy elevados. (Tradução nossa).

16 "La vivienda es el juez, y el hambre el reo. (Tradução nossa).

17 Cuando volví al hotel, encontré a una señora que vino a saludarme. Me dijo que el problema en Buenos Aires es la falta de viviendas. Que los alquileres son muy altos. (Tradução nossa).

18 Me despedí de las mujeres que habían venido y una me besó. (Tradução nossa).

19 El sueldo no alcanza para pagar una habitación decente. Si pagan el alquiler no pueden comprar comida. ¿Y a quién pueden recurrir los jóvenes para que les den comida? Después de un tiempo no tienen dinero, no tienen salud, no tienen moral. Los jóvenes no pueden concretar sus sueños, no pueden casarse ni tener un hogar porque el sueldo no les alcanza. La vida los va entristeciendo. Y se transforman en harapos humanos. Los gobiernos construyen casas prefabricadas. / Pero esta no es la solución./ Los ricos envían sus obras a los pobres. Pero es preciso que haya una reorganización. Necesitamos un mundo donde haya menos sufrimiento y más fraternidad. Aquí en la Argentina el frío es muy fuerte y hay hombres y mujeres que duermen bajo los árboles. Dicen que el pueblo de la actualidad es civilizado. Pero un hombre civilizado no puede permitir que otro hombre duerma bajo un árbol. (Tradução nossa).
} 
Este fragmento demonstra que, seja um discurso carolineano ou daquelas que a visitam, há uma perspectiva convergente a respeito das questões socioeconômicas argentinas. A identificação acontece não só nas percepções pessoais, mas, conforme visto anteriormente, na realidade compartilhada entre Brasil e Argentina. A presença de uma intelectual que se constrói na base da sociedade latinoamericana, comprometida com as causas populares e que está em uma posição de evidência proporciona acolhimento e divulgação de debates cruciais para as transformações sociais da região. As pautas da luta de Carolina Maria de Jesus, quando se expandem para outros países da América do Sul através de sua presença e de sua obra, proporcionam uma análise mais abrangente dos desafios divididos pelos países vizinhos e encaminham reflexões coletivas visando à resolução das desigualdades. Portanto, as mudanças de paisagem geográfica e populacional viabilizam o diálogo contrastivo sobre a pobreza.

O tema étnico-racial também é enfocado. A ausência de negros na Argentina é abordada desde o desembarque e a acompanha até os últimos dias. Inicialmente, há uma constatação empírica na qual a autora demarca não ver pessoas de pele preta. Depois, a instigação intelectual a conduz ao questionamento sobre o tema ao editor e também a respeito do preconceito racial. Diante da resposta de que há poucos pretos e da inexistência de atos discriminatórios, a pensadora não se contenta e se pergunta sobre a possibilidade do sistema escravocrata não constar na história do país vizinho. É notório o movimento reflexivo em torno do tópico e há uma demonstração da inquietação de Carolina Maria de Jesus em perscrutar o apagamento dos seus iguais no ambiente onde transita. Alguns eventos demonstram que há uma perplexidade local a respeito de sua negritude, como relata em Córdoba: "Caminhando pelas ruas eu era o centro dos olhares. As crianças me olhavam assustadas. E as pessoas paravam pra me olhar. Eu tinha a impressão de estar recebendo uma homenagem"20. (JESUS, 1963, p. 163).

Embora seja atravessada pelo estranhamento, devido à falta detectada através de seu olhar ou da presença do corpo escuro em meio a peles mais claras, Carolina Maria de Jesus não expressa um sentimento dolorido vivenciado em relação à cor da pele. Há uma afetação mútua, no entanto, a leitura da autora se realiza em duas vias: o questionamento histórico e a ressignificação. A primeira como um fundamento que explica a configuração étnico-racial daquela sociedade a partir da experiência do próprio país. Digo, uma vez que o sistema escravocrata é um dos meios pelos quais se realiza um povoamento massivo de população negra oriunda do continente africano no Brasil, ela desenvolve a hipótese de que o país vizinho não tenha se constituído demograficamente pelo mesmo processo. Por sua vez, a segunda abarca o aspecto individual, na medida em que a autora não aceita o olhar de inferiorização do outro em direção a si. Quando diz ter a impressão de receber uma homenagem, reafirma o lugar da escritora e inverte a ordem de forma que ela ocupa o espaço de protagonismo diante do olhar de contemplação admirada do outro.

Enquanto em terras argentinas há um movimento de compreensão de lacunas, o Uruguai é o único país, entre os inscritos no Diario de viaje, onde ela interage diretamente com a comunidade negra. Recebida com tambores e um cartaz escrito "Bem-vinda Carolina", declama poesias, vai ao Club Social Desportivo, conversa com um deputado negro, tira fotos e elogia a beleza das mulheres e meninas pretas. Porém, o contato não se restringe aos espaços afrocentrados, pois encontra seus irmãos

20 Caminando por las calles, yo era el blanco de las miradas. Los niños me miraban asustados. Y la gente se paraba para mirarme. Yo tenía la impresión de estar recibiendo un homenaje. (Tradução nossa). 
nos demais locais onde circula. Diz "tenho a impressão de estar sonhando"21 (JESUS, 1963, p. 155), no dia 13 de dezembro de 1961, ao ver vários negros comprando o livro, olhando para ela e sorrindo na fila de autógrafos. No diário, a satisfação da autora diante da exaltação negra ao livro é notória e demonstra a alegria de ver o acesso do seu grupo à obra que divulga.

Finalmente, em Santiago do Chile, as vivências sobre o tema, no que tange à primeira visita, não são agradáveis. Carolina Maria de Jesus vive episódios de racismo, classismo e sexismo em distintos momentos do seu trajeto pela capital. $O$ fato de ser uma mulher negra independente provoca desconforto e a autora percebe o incômodo dos demais. Além do episódio narrado no tópico anterior sobre a recepção descortês no aeroporto, há uma sucessão de eventos relatados nos quais as atitudes discriminatórias por parte de alguns membros da sociedade são evidentes. Quando convidada para um almoço com outros escritores na casa de Rubén Azócar, tem uma recepção acolhedora e mostra apreço pelo ambiente. Porém, no momento em que o anfitrião pega um gravador para registrar a conversa, ela senta-se ao lado de Benjamín Subercaseaux que, após uma série de elogios aos encantos chilenos, dirige-se à brasileira com um discurso racista: “- Carolina: a senhora pode admirar as belezas do Chile como turista. Porém, não pense em viver aqui, porque nós, os chilenos, não gostamos de negros, não gostamos de judeus, não gostamos de sírios” (JESUS, 1963, p. 175) ${ }^{22}$. No diário, expressa o choque emocional diante das palavras do autor e o inscreve esteticamente através do frio:

Foi um choque emocional porque eu nasci no Brasil e nunca ouvi um branco dizer "negra" em tom depreciativo. Os brancos do Brasil querem extinguir os preconceitos; os sírios prosperam, e os judeus nos favorecem porque criam fábricas no país, empregando brasileiros e estrangeiros que moram no Brasil. No meu país a cor da pele não tem importância. Apenas as atitudes.

Sentia muito frio.

Tinha a impressão de estar no Polo Norte em um iceberg. Levantei e fui me esquentar perto do fogo onde faziam o churrasco.

A nora do senhor Rubén Azocar serviu o jantar. Só que eu não jantei. A fome e minha alegria desapareceram com as palavras duras do escritor chileno. Ele acha que o negro não tem sensibilidade. (JESUS, 1963, p. 176) $)^{23}$.

Sabe-se que os aspectos étnico-raciais presentes em sua produção ainda são objetos de debate, pois a afirmação da negritude bem como o enfrentamento à discriminação coexistem com o discurso de uma igualdade entre as pessoas independente do fenótipo. É imprescindível lembrar, conforme destaca José Carlos Gomes da Silva (2009), que as teorias da democracia racial estavam em destaque no Brasil no período em análise. Logo, como uma intelectual atenta, Carolina Maria de Jesus apresenta os debates do seu tempo nos escritos, porém também imprime as experiências do sujeito negro no

21 Yo tenía la impresión de estar soñando. (Tradução nossa).

22 - Carolina, usted puede admirar las bellezas de Chile como turista. Pero no piense en vivir aquí, porque a nosotros los chilenos no nos gustan los negros, no nos gustan los judíos y no nos gustan los sirios. (Tradução nossa).

23 Fue un shock emocional porque yo nací en Brasil y nunca oí un blanco decir "negra" en tono despectivo. Los blancos del Brasil quieren extinguir los prejuicios; los sirios prosperan, y los judíos nos favorecen porque crean fábricas en el país, empleando a brasileños y extranjeros que viven en el Brasil. En mi país el color de la piel no tiene importancia. Solamente las actitudes./ Sentía mucho frío./Tenía la impresión de estar en Polo Norte, en un iceberg. Me levanté y fui a calentarme cerca del fuego donde asaban el churrasco./ La nuera del señor Rubén Azocar sirvió la cena. Pero yo no cené. El hambre y mi alegría se ausentaron con las palabras del escritor chileno. Él piensa que el negro no tiene sensibilidad. (Tradução nossa). 
mundo - principalmente da mulher - em uma sociedade estruturada no racismo. $O$ fragmento citado ilustra a afirmação, pois expressam ambos os movimentos. A escritora descreve uma coexistência pacífica das raças no país e, no mesmo parágrafo, elabora através da metáfora do frio a dor proveniente da opressão e assinala a estratégia de desumanização de pessoas pretas.

No entanto, também é no Chile onde vive uma experiência de reconhecimento de seus pares como uma intelectual. Em uma sessão de autógrafos na livraria Orbe, recebe o convite do diretor da Escola Internacional de Verão de Concepción para participar de um evento acadêmico no ano seguinte, especificamente janeiro de 1962. Carolina Maria de Jesus aceita e regressa às terras chilenas em mencionado período para proferir a palestra "A América precisa de outra Independência”, na universidade, e a estadia revela uma outra relação com o país. Ela assiste conferências de pensadores dos EUA, Cuba, Peru, Rússia e mantém uma postura reflexiva e crítica diante do que escuta. No seu discurso, aborda temas como a importância da educação e da coletividade dos trabalhadores, a emigração, a cultura, o desarmamento, a reforma agrária, a maternidade. Ela pronuncia um discurso que abarca os principais debates latino-americanos. Diante do público, apresenta a potência preta de uma pensadora e transformadora do mundo.

Além dos assuntos conjunturais discutidos ao longo das exposições pessoais, as entrevistas concedidas constam no texto do Diario de viaje em estilo direto. Desta forma, o leitor acessa o conteúdo de interesse da mídia e as respostas da autora em algumas entrevistas. Vale dizer que utilizo o pronome indefinido, porque, durante a pesquisa, encontram-se materiais nos arquivos que não figuram no diário. Esclarecido o pormenor, reitera-se a relevância dos diálogos para que possamos conhecer as pautas dos meios de comunicação para desvelar seus pontos de vista e considerações durante a turnê.

Nos três países, os questionamentos não se restringem ao universo literário. A designação de escritora da favela conduz grande parte das perguntas para uma via mais sociopolítico e econômica. Os jornalistas argentinos, uruguaios e chilenos questionam sobre as condições dos que vivem nos quartos de despejo da cidade e buscam a perspectiva da autora. Constantemente, ela denuncia o alto custo de vida dos grandes centros e a precariedade daqueles que habitam nas margens que os circundam. A imprensa internacional mostra curiosidade a respeito das reflexões da intelectual sobre seu país e aquele que visita. Carolina Maria de Jesus responde com segurança e clareza sobre o que lhe interrogam, embora se sinta incomodada por falar menos sobre literatura do que gostaria - "Já estou cansada de ouvir críticas sobre a situação do Brasil. Eu não sou política. $O$ único que me interessa são os livros" ${ }^{24}$ (JESUS, 1963, p. 171). O compromisso com a verdade lhe rende problemas com a editora brasileira, especificamente com Dona Adelia, uma vez que há repreensões sobre suas falas na Argentina referentes aos problemas nacionais. No entanto, apesar da tristeza diante da censura que querem impor em seus discursos públicos, ela defende e mantém o engajamento, tendo em vista que compreende seu papel social enquanto uma mulher negra periférica que, naquele momento, goza de projeção internacional. Reproduzo o diálogo datado de 25 de novembro:

- Estou irritada com você por dizer na Argentina que existe fome no Brasil.

- Sim existe. E todo mundo sabe - respondi energicamente.

24 Ya estoy cansada de oír las críticas de la situación de Brasil. Yo no soy política. Lo único que me interesa son los libros. (Tradução nossa). 
- Existe fome no norte. Existe fome entre os trabalhadores. Existe fome no mundo. Precisamos de uma reforma social. O povo já não pode suportar mais esta desorganização. Trabalham em excesso e o salário que recebem não dá para nada. (JESUS, 1963, p.152-153) ${ }^{25}$.

O texto citado demonstra a preocupação da intelectual em dar visibilidade a um dos problemas mais graves que seu país enfrenta e, como a prática descrita em parágrafos anteriores, após mencioná-lo, a fome, apresenta propostas que possibilitem uma resolução: uma reforma social. Ela tem consciência da responsabilidade que mantém como uma representante do povo. No dia anterior, quando arruma as malas para o retorno ao país, reflete sobre a situação educacional brasileira em comparação com a argentina. Através de uma análise histórica, denuncia o assalto colonial dos portugueses e o desinteresse no desenvolvimento local, demonstrando a compreensão de uma origem estrutural da questão. Após a elucubração, descreve a relevância de pensadores periféricos na construção do pensamento, principalmente social, do país, uma vez que os acadêmicos oriundos das classes abastadas se acovardam diante de debates essenciais. Afirma: "Estas são verdades que os escritores da Academia veem, mas não tem coragem de dizer. Fez falta que uma escritora de pele preta que surgiu do lixo, tenha que dizê-lo. E assim vou ganhando amigos e inimigos." (JESUS, 1963, p. 150) ${ }^{26}$.

Os aspectos trabalhados no tópico exemplificam a consciência da escritora sobre seu papel como pensadora e artista nacional e internacionalmente. Ela faz parte do grupo que bell hooks designa como "intelectuais comprometidos e preocupados com mudanças sociais radicais" (hooks, 1995, p. 464). A viagem para divulgar Quarto de despejo possibilita não apenas a projeção internacional de sua obra no exterior, mas uma compreensão mais abrangente de suas inquietações sobre o mundo. Na trajetória, a escritora possibilita um intercâmbio no qual reelabora seus pensamentos a partir de um contato mais amplo com a realidade latino-americana e, ao mesmo tempo, permite que a região olhe para si e se reconfigure por meio de uma perspectiva que a representa de maneira mais intrínseca. Designo com o termo deslocamentes a série de movimentos provocados pelo trânsito de uma intelectual negra que assume, de maneira engajada, a conduta de sujeito que atua no mundo com o fim de afetá-lo e, consequentemente, transformá-lo. Elucida-se o termo de maneira mais pormenorizada no artigo Del recoger al recorrer: desplaza-mentes de Carolina Maria de Jesus por Argentina:

As habilidades reflexivas e criativas de quem se desenvolveu nas margens somadas à presença do corpo
negro de uma pensadora sul-americana em trânsito propiciam uma desestabilização das estruturas. É
uma reconfiguração na qual ela se posiciona como sujeito ativo que, ao ocupar os espaços que, ao longo
de séculos foram negados aos indivíduos periféricos, permitem a abertura de brechas nos muros do
estabelecido, geralmente permeado de preconceitos. Desta maneira, promove uma reformulação das
representações do que se concebe como: moradora de favela, intelectual, mulher, negra, viajante, entre
tantas outras categorias. É um convite para que revisitemos nossas próprias concepções como latino-
americanos, através de uma perspectiva aberta à pluralidade e comprometida com nossas verdadeiras
origens, sem adotar, arbitrariamente, o que dizem que somos ou os desejos que nos imputaram sobre

25 - Estoy enojada con usted por decir en la Argentina que hay hambre en el Brasil./ - Sí que la hay. Y todos lo saben - respondí enérgicamente. / - Hay hambre en el norte. Hay hambre entre los obreros. Hay hambre en el mundo. Necesitamos una reforma social. El pueblo ya no puede seguir soportando esta desorganización. Trabajan en exceso y el sueldo que reciben no les alcanzan para nada. (Tradução nossa).

26 Estas son verdades que los escritores de las Academias ven pero no tienen coraje de decir. Hizo falta que una escritora de piel negra que surgió de los basurales, tenga que decirlo. Y así voy ganando amigos y enemigos. (Tradução nossa). 
o que devemos querer ser. O deslocamento de Carolina Maria de Jesus é uma potência para que o sul consiga parir-se a partir de si. (LEAL, 2021) ${ }^{27}$.

Azoilda Loretto da Trindade ensina que "a realidade é complexa, e o conhecimento e sua construção não se dão linearmente, mas em fluxos, movimentos, redes e conexões, nas relações entre as pessoas e o mundo" (TRINDADE, 2006, p. 101). Carolina Maria de Jesus é uma autora que comprova esta afirmação, uma vez que sua produção é fruto de mobilidades e contatos. Quando transita pelo exterior, amplia a trama de diálogos que estabelece. No entanto, como um corpo preto que se move por locais tradicionalmente interditados pelo racismo provoca uma série de reações por onde percorre e movimenta as ideias daqueles que a encontram sobre o que engloba ser viajante e intelectual. Assim, ela desloca as mentes e reconfigura a ordem vigente, uma vez que abre brechas no pensamento sobre o estabelecido - geralmente permeado de preconceitos - e amplia as concepções sobre quem somos e o que reivindicamos enquanto latino-americanos.

\section{CONCLUSÃO}

Conforme Grada Kilomba adverte em Memórias da Plantação, o racismo cria uma hierarquização na qual "negritude significa não somente 'inferioridade', mas também 'estar fora do lugar"' (KILOMBA, 2019 , p. 56). Sabe-se que, ao longo de séculos e ainda hoje, a mulher negra oriunda da periferia ainda não é reconhecida como pertencente a determinados espaços. A presença da pele preta em ambientes como os que a escritora frequenta no Brasil e no exterior - aeroporto, avião, hotel, livraria, universidade - até hoje é motivo de estranhamento. Embora a estrutura em voga insista em ocultar, apagar e exterminar nossos corpos dos lugares, principalmente aqueles onde o poder se estabelece, resistimos e nos apropriamos do direito de atuar existencial, criativo e epistemologicamente no mundo.

Como uma escrevida das letras ${ }^{28}$, Carolina Maria de Jesus confronta o sistema já na década de 1960 e ocupa espaços nacionais e internacionais que tradicionalmente lhe são negados. Neste movimento por diversos países com sua pele e suas ideias, afeta e é afetada pelo meio e pelas pessoas, pois, seguindo as trilhas de Trindade mais uma vez, aprendemos que "afetividade nos reporta ao corpo e porque os corpos são potências, possibilidades, amorosidade". (TRINDADE, 2006, p. 102). Seu corpo de mulher negra em trânsito mostra a criatividade capaz de desestabilizar ordens opressoras e conceber multiversos mais colaborativos e plurais.

No entanto, este não é um empreendimento individual. Em conformidade com o que Angela Davis atenta em palestra conferida na Bahia em 2017: "Quando a mulher negra se movimenta, toda a estrutura da sociedade se movimenta com ela” (ALVES, 2017). Tendo em vista que este grupo compõe

\footnotetext{
27 Las destrezas reflexivas y creativas de quien se gestó en los márgenes, sumadas a la presencia del cuerpo negro de una pensadora sudamericana en tránsito, propician un sacudimiento de los esquemas. Es una reconfiguración en la que ella se pone como sujeto activo que, al ocupar los espacios que han sido por siglos negados a los sujetos periféricos, propicia la apertura de grietas en los muros de lo establecido, generalmente plagado de prejuicios. De esta manera, promueve una reformulación de las representaciones con las que se siente caracterizada: habitante de la favela, intelectual, mujer, negra, escritora, viajera, entre tantas otras categorías. Es una invitación a que revisitemos nuestras concepciones sobre nosotros mismos, latinoamericanos, desde una perspectiva abierta a la pluralidad y comprometida con nuestros verdaderos orígenes, sin adoptar arbitrariamente lo que dicen que somos o los deseos que nos han planteado sobre lo que debemos querer ser. El desplazamiento de Carolina Maria de Jesus es una potencia para que el sur logre parirse desde adentro. (Tradução nossa).

28 Termo utilizado por Marcelle Leal em Poéticas das Sombras: de projeções a sujeitos do conhecimento (LEAL, 2017) para caracterizar a escritora de Sacramento.
} 
a base da sociedade, a filósofa norte-americana compreende que ele desestabiliza a ordem a partir de sua atividade. Portanto, entende-se que a dinâmica de Carolina Maria de Jesus, em deslocamentos e deslocamentes, é fundamental para impulsionar a América Latina a se repensar e reordenar a partir de suas bases de forma que mostremos quem somos e o que queremos ser em toda nossa potência e afetividade.

\section{REFERÊNCIAS}

ALMEIDA, Silvio Luiz de. Racismo estrutural. São Paulo: Sueli Carneiro; Pólen, 2019.

ALVES, Alê. Angela Davis: "Quando a mulher negra se movimenta, toda a estrutura da sociedade se movimenta com ela”. El País. Salvador, 27 de jul de 2017. Seção Brasil. Disponível em: https://brasil.elpais. com/brasil/2017/07/27/politica/1501114503_610956.html. Acesso em: 28 set. 2021.

COLLINS, Patricia Hill. Aprendendo com a outsider within: a significação sociológica do pensamento feminista negro. Revista Sociedade e Estado, Brasília, v. 31, n. 1, p. 99-127, jan./abr. 2016. Disponível em: https://doi.org/10.1590/S0102-69922016000100006. Acesso em: 20 set. 2021.

hooks, bell. Intelectuais negras. Revista Estudos Feministas, Florianópolis, v. 3, n. 2, p. 464-478, 1995. Disponível em: https://periodicos.ufsc.br/index.php/ref/article/view/16465/15035. Acesso em: 26 set. 2021.

JESUS, Carolina Maria de. Diário de viaje. In: JESUS, Carolina Maria de. Casa de ladrillos. Buenos Aires: Abraxas, 1963.p. 128-191.

KILOMBA, Grada. Memórias da plantação: episódios de racismo cotidiano. Rio de Janeiro: Cobogó, 2019.

LEAL, Marcelle Ferreira. Del recoger al recorrer: desplaza-mentes de Carolina Maria de Jesus por Argentina. Revista Transas, Letras y Arte de América Latina, Buenos Aires. 2021. Disponível em: https://www. revistatransas.com/2021/07/15/mariadejesus-leal/. Acesso em: 28 set. 2021.

Poéticas das sombras: de projeções a sujeitos da literatura. 2017. 267 f. Tese (Doutorado em Ciência da Literatura) - Faculdade de Letras e Artes, Universidade Federal do Rio de Janeiro, Rio de Janeiro, 2017.

LEÃO, Ryane. Tudo nela brilha e queima. São Paulo: Planeta Brasil, 2017. Ebook.

SILVA, José Carlos Gomes da. Carolina Maria de Jesus e os discursos da negritude: literatura afro-brasileira, jornais negros e vozes marginalizadas. Revista História \& Perspectivas, [S. 1.], v. 1, n. 39, 2009. Disponível em: http://www.seer.ufu.br/index.php/historiaperspectivas/article/view/19189. Acesso em: 26 set. 2021.

TRINDADE, Azoilda Loretto da. Fragmentos de um discurso sobre afetividade. In: BRANDÃO, Ana Paula (org.). Saberes e fazeres, v.1: modos de ver. Rio de Janeiro: Fundação Roberto Marinho, 2006. p. 101-112. 